\title{
Identifying "high risk situations" for preventing AIDS
}

\author{
Anthony B Zwi, Antonio Jorge R Cabral
}

\begin{abstract}
If disease is an expression of individual life under unfavourable conditions, then epidemics must be indicative of mass disturbances of mass life.
\end{abstract}

\section{Rudolph Virchow ${ }^{1}$}

The terms used to describe the HIV epidemic, to research its origin and aetiology, and to quantify its magnitude have varied over time. They influence how we perceive the disease, its impact on society, and its control. The terms "risk groups" and, more recently, "risk behaviours" have been used in developing research and intervention strategies. Both terms have limitations: "risk groups" may be stigmatising and non-specific; "risk behaviours" may fail to identify the determinants of behaviour so that interventions will be only partially effective. They fail to recognise that health is far more readily determined by social conditions than by individual behaviour and health services. $^{2}$

\section{"High risk situations" and social contexts}

This paper argues the need for a new term-high risk situation-to describe the range of social, economic, and political forces that place groups at particularly high risk of HIV infection.

A number of such circumstances have been described. Wilson et al, for example, identified impoverishment, rapid urbanisation, anonymity of city life, migrant labour, poor wages, and dependency of women as the main factors leading to women seeking sex in exchange for money in Bulawayo, Zimbabwe. ${ }^{3}$ Workers in Kenya found that prostitutes from the lower social classes had more than double the rate of HIV seropositivity than prostitutes from the upper socioeconomic strata. ${ }^{4}$ Poorer women were paid 10 to 30 times less per encounter than their higher class colleagues and had about eight times as many partners per year. ${ }^{4}$ In Uganda, commercial sex workers often have no other employment, are uneducated, are frequently supporting family members in the rural areas, have a sexually transmitted disease but poor access to health services, and survive in a context of landlessness, poverty, migration to urban areas, and the aftermath of war and repression.

Rates of HIV infection and AIDS in black people in South Africa are increasing rapidly and major public health initiatives are required. ${ }^{5}$ The migrant labour system draws large numbers of men to industrial and mining centres. They almost always leave their families behind, seeing them infrequently, and are housed in single sex hostels. These men seek companionship with women living near their place of work, predictably posing a high risk for multipartner sexual activity and the spread of sexually transmitted diseases and HIV infection. ${ }^{6}$ Migrant labour systems worldwide present similar high risk situations. ${ }^{7}$ Women remaining in impoverished rural areas, dependent on remittances from their absent family members, may resort to commercial sex to supplement their incomes and reduce their dependency. Their entry to a high risk situation is often characterised by powerlessness and little control over their sexual health.

HIV infection in the Philippines is partly related to the sexual services provided by "hospitality women" to $\frac{\rho}{\partial}$ American servicemen; in Thailand it relates to the 3 commercial sex industry and the lack of alternative forms of employment for many young men and $\omega$ women. Politicians, teachers, soldiers, businessmen, and others in positions of power may obtain sex on $\vec{\sigma}$ their terms, often at a health risk to those providing such services.

Population movements by individuals or groups pose other high risk situations. Truck transport brings drivers into contact with women along the route, many $\vec{A}$ of whom depend on sex for their livelihood. Seafarers, aircraft crew, and others who travel widely and frequently may be placed in high risk situations.

Social disruption due to wars, especially counterinsurgency wars, seems to have affected the spread of HIV in Mozambique. ${ }^{8}$ The complex interaction of $\emptyset$ economic sabotage, destruction of infrastructure, and banditry creates marginalised and displaced 0 populations at increased risk of HIV infection from casual sexual contacts (figure), and this is exacerbated by limited access to sanitation and health services.

Impoverishment and disenfranchisement in the drug using population of the United States may be associated with a culture of risk taking, reflecting both the inadequacy of services and the social marginalisation and stigmatisation of this group.

The identification of these high risk situations makes it possible to predict where the epidemic will next strike: the explosion among commercial sex workers and injecting drug users in Asia was entirely predictable once the virus was introduced there. Epidemics in populations of migrant workers, in rapidly urbanising populations, and among the indigenous populations of the world much affected by sexually transmitted 9 diseases and alcohol use, are likely next targets.

\section{Characteristics of high risk situations}

The characteristic features of high risk situations vary, but some general observations may be relevant. $\frac{\omega}{\sigma}$ Many of these situations occur where there is diminished concern about health, increased risk taking, and reduced social concern about casual sexual relation- $\stackrel{\Phi}{\Phi}$ ships. In some circumstances, such as refugee populations and street children, those affected may be 0 struggling to feed themselves, and even if they were $\mathbb{D}$ aware of HIV it would be considered relatively un- $\frac{\Omega}{\square}$ important. A high turnover of sexual partners, often 응 in exchange for money or goods, may be present. The ability to practise safer sex may be impaired by the use of of alcohol and other addictive drugs as well as a lack of information, resources, and power. Those aware of the

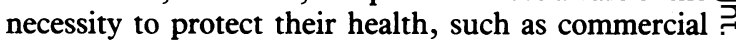
sex workers in many parts of the world, may be unable to ensure that their paying (and even less their nonpaying) partners use condoms. All these social contexts 


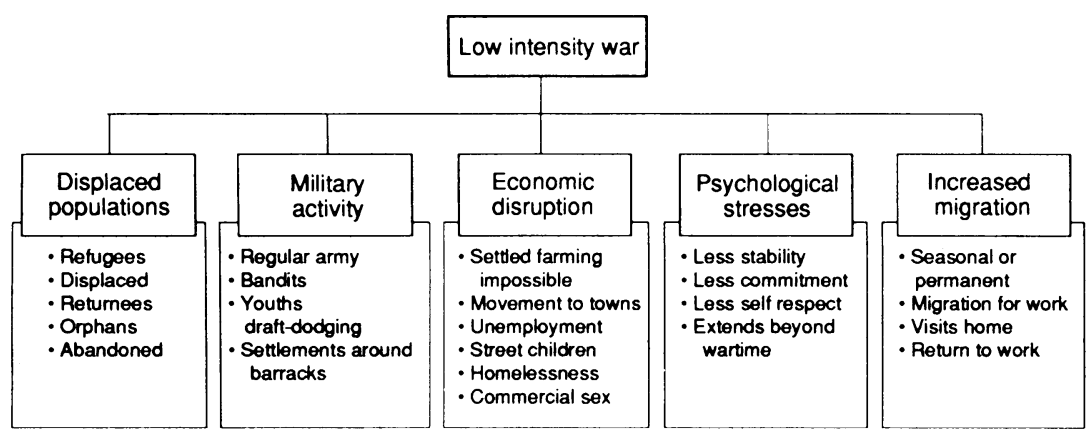

Some of the mechanisms whereby low intensity war may place populations in high risk situations should recognise the political character of patterns of health and disease; should be rooted in popular struggles for a more just and humane society; and must consider the specific worries and concerns of the people involved. ${ }^{11}$ Others have argued similarly,${ }^{14}$ highlighting the Ottawa charter for health promotion, which identifies the importance of creating supportive environments, strengthening community action, developing personal skills, reorienting health services, and replacing the dominance of bureaucracies with control by communities. ${ }^{15}$ Freudenberg has argued that AIDS prevention programmes must be based within the culture of the target population but at the same time must challenge those cultural values that place people at risk of HIV infection; they must be integrated into other community programmes around such issues as substance misuse and teenage pregnancy (or, we would add, migrant labour, population displacement, and rapid urbanisation); legitimate community organisations should be enlisted in the AIDS prevention effort; and support should be given to programmes taking a more political stance. ${ }^{16}$ Professionals may assist by making their skills and resources available to community organisations to help with research, training, and education.

As well as identifying more appropriate forms of health education, recognising high risk situations may also reveal the need for more fundamental change: stimulating development, creating income generating opportunities, and addressing global economic imbalances and Third World debt. ${ }^{17-19}$ In industrialised countries, too, part of the solution will entail reintegrating marginalised communities and providing a way out of the poverty and hopelessness traps. including social change. Bassett and Mhloyi $\mathrm{i}^{12}$ indicate the need for expanding women's limited options both technically (investigating alternatives to condoms that women can control) and socially (by promoting other sources of employment). In South Africa, the National Union of Mineworkers focuses on the need to change the context in which unsafe sex occurs. ${ }^{6}$ At the same time, union members are urged to reduce their high risk behaviour by understanding its origins and how they will collectively confront HIV.

Conventional health education is likely to fail in high risk settings: health services may be underdeveloped and in any case the techniques used may be limited in their ability to penetrate affected communities. Other educational programmes aimed at changing individual behaviour - encouraging people to stop smoking, drink less alcohol, or use preventive health services-have generally met with limited success. ${ }^{11}$ Identifying the social context and involving community members in developing appropriate messages may facilitate the emergence of more appropriate programmes. ${ }^{13}$

Through exploration of high risk situations and understanding their influence, new opportunities for examining how social structures relate to ill health emerge. Developing new terms and concepts and struggling for their legitimacy helps their absorption into research, medical practice, and public health interventions. This is not to argue that all efforts should be directed at, or should wait for, social change - the delay in achieving this might cause many more deaths - but is an argument for considering the structural dimensions in each setting. It may also assist in identifying who should be involved in preventive activity: those drawn from a similar high risk background may be the most acceptable and effective at promoting health and in identifying how educational messages should be phrased to take account of local knowledge and sensitivities.

Towards a meaningful approach to HIV education and health promotion

Effective health promotion requires informational, behavioural, social, legal, and economic interventions;

\section{Conclusion}

Much literature on AIDS fails to identify the context in which HIV is transmitted: high levels of preventable disease, inadequate health resources, and a background of poverty, rapid urbanisation, commercial sex, social upheaval, and community marginalisation. ${ }^{17} 18$ Recognising high risk situations will help focus attention on the determinants of health and may help predict which populations are likely to be affected by rapid spread of HIV infection. It will also identify the appropriate role of health services and the importance of stimulating and supporting community based initiatives. In such settings appropriate identification of the problems, the correct use of language and research, and meaningful interventions can be

Research should attempt to elucidate the complex interactions between high risk behaviours and their structural determinants. The development of appropriate concepts to debate these issues will help influence researchers and policy makers to consider some of the more far reaching requirements for health promotion. They will focus not only on individual behaviour change but on the determinants of behaviour, including the social, political, and economic characteristics of society. Such an approach will help open the way to promoting those changes in behaviour and society which will seriously impede the development of the global HIV epidemic.

\footnotetext{
Eisenberg L. Rudolf Karl Virchow, where are you now that we need you? $A m f$ Med 1984;77:524-32.

McKeown T. The role of medicine. Oxford: Basil Blackwell, 1979.

3 Wilson D, Sibanda B, Mboyi L, Msimanga S. A pilot study for an HIV prevention programme among commercial sex workers in Bulawayo, Zimbabwe. Soc Sci. Med 1990;31:609-18.

4 Kreiss JK, Koech D, Plummer FA, Dube G. AIDS virus infection in Nairobi prostitutes: spread of the epidemic to East Africa. $N$ Engl $\mathcal{f}$ Med 1986;314:414-8

5 Zwi AB, Bachmayer DE. HIV and AIDS in South Africa: what is a appropriate public health response? Health Policy and Planning 1990;5 316-26.
} contemplated and initiated. 
6 Jochelson K, Mothibeli M, Leger J-P. Human immunodeficiency virus and migrant labor in South Africa. Int $\mathcal{F}$ Health Serv 1991;21:157-73.

7 Hunt CW. Migrant labor and sexually transmitted disease: AIDS in Africa. 7 Health Soc Behav 1989:30:353-73.

8 Baldo M, Cabral AJR. Low intensity wars and social determinations of the HIV transmissions: the search for a new paradigm to guide research and control of the HIV-AIDS pandemic. In: Stein Z, Zwi A, eds. Action on AIDS in southern Africa. Maputo conference on health in transition in southern Africa, April 1990. New York: Committee for Health in Southern Africa, 1991 34-43.

9 Piot P, Holmes KK. Sexually transmitted disease. In: Warren KS, Mahmoud AAF, eds. Tropical and geographical medicine. 2nd ed. New York: McGraw Hill, 1988:894-910.

10 Rosenfield PL. Social determinants of tropical disease. In: Warren KS, Mahmoud AAF, eds. Tropical and geographical medicine. 2nd ed. New York: McGraw Hill, 1988:197-205.

11 Freudenterg $N$. Health education for social change: a strategy for public health in the US. International fournal of Health Education 1981;24:1-8.
12 Bassett MT, Mhloyi M. Women and AIDS in Zimbabwe: the making of an epidemic. Int $\mathcal{A}$ Health Serv 1991;21:143-56.

13 Freudenberg N, Lee J, Silver D How black and Latino community organizations respond to the AIDS epidemic: a case study in one New York City neighbourhood. AIDS Education and Prevention 1989;1:12-2.

14 Green LW, Raeburn JM. Health promotion. What is it? What will it become Health Promotion 1988;3:151-9.

15 Ottawa charter for health promotion. Health Promotion 1986;1:3-5. Freudenberg N. AIDS prevention in the United States: lessons from the firs decade. Int f Health Serv 1990;20:589-99.

17 Packard RM, Epstein P. Epidemiologists, social scientists, and the structure of medical research on AIDS in Africa. Soc Sci Med 1991;33: $771-94$.

18 Sanders D, Abdulrahman S. AIDS in Africa: the implications of economic recession and structural adjustment. Health Policy and Planning 1991;6: $157-65$

19 Nabarro D, McConnell C. The impact of AIDS on socioeconomic development. AIDS 1989;3 (suppl 1):S265-72.

\title{
Needs assessment, priority setting, and contracts for health care: an economic view
}

\author{
Cam Donaldson, Gavin Mooney
}

The publication of the Acheson report led to the proposal that directors of public health should be responsible for assessing the needs of their local populations. ' This idea was then taken up in the white paper on the NHS, which reaffirmed their responsibility to assess the needs of the population but as a means of informing health boards/authorities as purchasers of care. ${ }^{2}$ One way of informing the contracting process, it is thought, is to assess the health care needs of the population, to determine what health care should be provided and to what extent.

We propose here a method for determining priorities in health care based not on total needs assessment but on economic evaluation. We believe this method is more relevant for health care contracting. Its widespread use will ensure that, no matter what total needs are, health care resources are used in such a way as to maximise the benefits from them.

We first introduce the economic approach to priority setting and outline its advantages over needs assessment. Finally, we discuss how health care professionals might in practice use the economic approach in setting priorities and contracts.

\section{Setting priorities: the economic approach}

Setting priorities starts from the fact that resources are scarce. Contracting is an arrangement between purchasers and providers about both what to provide and what not to provide. If the aim is to maximise health gains to the community within the resources available priority setting should become an integral part of contracting.

Tackling one particular health problem denies society the opportunity of using those resources to tackle other health problems. There are opportunities forgone and thereby opportunity costs. The aim of priority setting is to ensure that the health benefits resulting from health care are maximised and that the opportunity costs of health care are minimised. This can be done only by comparing health care interventions with each other in terms of health gains produced for resources spent.

The economic approach to priority setting addresses two related questions: Is a health care intervention worth while? Given that it is worth while, what is the best way of providing it?

Policy questions often relate to changing the scale of a health care intervention-providing more of it or less of it. Evaluation must then take account not of the total costs and benefits of the whole programme but of the incremental (or marginal) costs and benefits (that is, the difference between costs and benefits before and after the change in scale).

A comparison using a league table of QALYs (quality adjusted life years) of some marginal costs and benefits is presented in table I. ${ }^{4-6}$ Certainly, QALYs can be criticised as measures of health ${ }^{7-10}$ but they are among the best measures currently developed. Consequently, assuming that the objective of health care policy is to maximise the contribution of health care resources to the health (defined here as QALYs) of the community, then more resources within the health care budget should be allocated to treatments with a low marginal cost per QALY and less to those with a high marginal cost per QALY gained. Thus, assuming all health care treatments available are those listed in table I, other things being equal, dialysis should be contracted and chiropody expanded; more QALYs would be produced without any increase in expenditure.

TABLE I-Illustrative marginal cost per QALY league table

\begin{tabular}{lc}
\hline Treatment & $\begin{array}{c}\text { Marginal cost per } \\
\text { QALY gained } \\
\text { (1988 prices) } \\
\text { Special chiropody at home (>75 years) }\end{array}$ \\
\hline GP's advice to give up smoking & 199 \\
Chiropody in a clinic (ages 60-75) & 238 \\
Pacemaker implantation & 603 \\
Hip replacement & 832 \\
Valve replacement for aortic stenosis & 891 \\
Coronary artery bypass grafting: & 1096 \\
Severe angina, left main disease & 1231 \\
Severe angina, triple disease & 1505 \\
Moderate angina, left main disease & 1584 \\
Kidney transplantation & 6072 \\
Haemodialysis at home & 13069 \\
Haemodialysis in hospital & 16634 \\
\hline
\end{tabular}

Sources: Williams, ${ }^{+5}$ Bryan et al.

Setting priorities: the needs assessment approach

The traditional epidemiological approach to needs assessment would appear to be to measure the total amount of ill health in the community, categorised by disease, and then use this information to set priorities for allocating resources between different diseases. "Need" could be measured by lives lost, life years lost, morbidity, or loss of social functioning.

Using some broad definition of need epidemiologists would then set priorities using data of the sort presented in table II. The first priority in health care resource allocation, and in purchasing care, would go to ischaemic heart disease.

Nevertheless, it is not clear from such data how 